Check for updates

Bengaluru, India

emailpriyanka@gmail.com

Cite this as: BMJ 2021;372:n278

http://dx.doi.org/10.1136/bmj.n278

Published: 10 February 2021

\title{
Covid-19: India's slow moving treatment guidelines are misleading and harming patients
}

\author{
The science of covid-19 treatments is fast moving. However, India's health ministry is failing to keep \\ pace, leaving a confusing and harmful vacuum, writes Priyanka Pulla
}

\section{Priyanka Pulla freelance journalist}

When Santosh Gaggar was admitted to hospital in December 2020 with severe covid-19 her doctors suggested an experimental treatment: plasma therapy.

Her doctors at the Hiranandani Hospital in Powai, Mumbai, told Santosh's family that its efficacy was uncertain, but it had worked in other patients and considering Santosh's condition they wanted to try it.

What the family didn't know, however, was that in November India's top government medical research agency, the Indian Council of Medical Research (ICMR), ${ }^{1}$ had explicitly advised against plasma therapy in patients like her who have had symptoms for over 10 days and have already developed immunoglobulin G in response (see box). Santosh's antibody levels were confirmed by blood tests.

ICMR's advice is based on three randomised controlled trials, including one done by ICMR itself, which found that plasma did not prevent death in patients who were moderately ill. Asked why Santosh's doctors administered the intervention to a patient who did not meet the criteria, Swapnil Mehta, a pulmonologist at Hiranandani Hospital, said that while he was aware of the ICMR guidelines, they decided to try plasma as a "last resort."

At the end of 2020, plasma therapy was being used routinely in many patients across India and was given the endorsement of political leaders. Despite the ICMR advice, guidelines from the health ministry, as well as multiple states, continue to recommend it for moderately and severely ill patients

"We are using our resources, equipment, blood banks and healthcare personnel for an intervention that does not work," says S P Kalantri, an internal medicine specialist at Maharashtra's Mahatma Gandhi Institute of Medical Sciences.

Plasma therapy is just one treatment being given in India to patients for whom there is little evidence of its benefit. The problem, many experts say, is the failure of the central and various state governments to keep up with the rapidly updating science around covid-19 and its treatments. The health ministry hasn't updated its covid-19 treatment guidelines since last July. "The science becomes obsolete even before the proverbial ink dries in this era," says Kalantri.

In a country like India, where powerful prescription drugs are often available over the counter, disincentivising the use of unproved medicines is as important as recommending the use of ones that have been proved to work, says Lancelot Pinto, a pulmonologist at Mumbai's P D Hinduja Hospital. But government guidelines have done a poor job of this, he says.

The reasons for this are complicated. For one thing, it is difficult in a pandemic to treat a patient with only minimal care. "This pressure to 'do something' might nudge physicians towards creating guidelines for unproven drugs that are either considered innocuous, or may have shown promise in animal studies or theoretical models, based on biological pathways," says Pinto. "They think, 'Let's give it our best shot, even if it may not work. What's the harm?'”

Another reason is that constantly reviewing the rapidly changing evidence in a pandemic is an intensive exercise, which individual hospitals in India might find easier to do than state and central governments.

“The public health system is a huge enterprise," says Joy Mammen, a pathologist at the Christian Medical College, Vellore, "Making quick changes to treatment protocols to reflect evidence may be challenging for them, given that they have to coordinate with people across institutions, across states, across local administrations."

\section{Using drugs without evidence}

Among the covid-19 treatments that have been heavily used in the last 12 months despite question marks about their efficacy are the anti-inflammatory drugs tocilizumab and itolizumab and the antivirals favipiravir and hydroxychloroquine.

While the manufacturers of favipiravir and itolizumab have claimed efficacy of these drugs based on inconclusive clinical trials, large randomised trials have shown no benefit on mortality from hydroxychloroquine. For plasma and tocilizumab, randomised trials suggest that they may help only during a small time frame-very early in the disease course for plasma, and within 24 hours of admission into the intensive care unit for tocilizumab. ${ }^{2}$

Yet, India's ministry of health and state governments have included the drugs in their covid-19 treatment guidelines, often going against evidence from randomised trials and triggering the widespread and routine use of these drugs by doctors. A Twitter search for plasma and tocilizumab shows several requests from patients' families looking urgently for them in the second half of 2020, at a time when trials had failed to confirm plasma's efficacy in moderately and 
severely ill patients, and tocilizumab's efficacy at multiple stages of the disease.

No medical intervention is harmless, says Kalantri, which to him means that using any drug indiscriminately without evidence of efficacy is unjustified.

The BMJ contacted members of teams that drafted the health ministry guidelines and guidelines for three state governments: Karnataka, Maharashtra, and Kerala. The BMJ also contacted the health ministry but did not receive a response.

K S Sathish, a pulmonologist who helped develop Karnataka's guidelines, agreed that hydroxychloroquine and itolizumab had no place in covid-19 treatment and would be removed from the guidelines soon. At the time of writing, Karnataka state guidelines have not been updated since October 2020, and continue to recommend these drugs.

Shashank Joshi, an endocrinologist at Mumbai's Lilavati Hospital and Research Centre, who helped develop Maharashtra's treatment guidelines, said that although the government was recommending tocilizumab, itolizumab, and plasma, these drugs had been flagged as "experimental" and it was up to doctors to decide whether to use them.

Another doctor, who helped develop Kerala's guidelines and spoke to The BMJ under anonymity, said the Kerala government was forced to include hydroxychloroquine in their recommendations because the health ministry was continuing to recommend it. He said that it was difficult to rely entirely on randomised controlled trials carried out in other countries for treatment decisions in India, and that the lack of trials in the Indian population made it harder to create guidelines.

\section{Approvals without evidence}

Medical experts have also questioned the hasty approval of drugs for treatment of covid-19 by the drugs controller general of India (DCGI), India's top drug regulator.

One example is favipiravir, an influenza drug originally developed by the Japanese firm Fujifilm. In June, an Indian firm, Glenmark Pharmaceuticals, claimed that its randomised controlled trial of 150 patients had found the drug to be effective, ${ }^{3}$ leading to the DCGI approving the drug for covid-19 treatment. But critics countered that the Glenmark trial had failed to show the drug's benefits conclusively.

Despite the inconclusive results, favipiravir's approval by the DCGI led to several state governments including the drug in their guidelines, and to doctors using it widely. "In Mumbai, this drug is being prescribed like tap-water. It has become difficult for physicians to refuse to give it to patients, because patients are demanding it," says Pinto.

Such overuse of a drug whose efficacy is unknown is not without downsides, Pinto points out. Patients treated with favipiravir may have a false sense of security and may delay treatment when their symptoms worsen. Furthermore, as the Glenmark trial found, patients receiving favipiravir were more likely to suffer adverse events such as altered liver function and pneumonia.

Just a month after the approval of favipiravir, the DCGI approved itolizumab, based on a randomised trial of only 30 people,,$^{4}$ causing surprise among medical experts. The Bengaluru based firm Biocon had marketed this drug as a less expensive substitute for tocilizumab, which was already widely used at the time to treat the inflammatory phase of covid-19. But at least four randomised trials published since then, which recruited patients at various stages of covid-19, failed to show that tocilizumab cut deaths. ${ }^{5-8}$

This complexity isn't reflected in the health ministry's tocilizumab recommendation, which remains unchanged since July. The widespread use of tocilizumab at that time led to rises in the price of the drug and created a black market for it. In addition to tocilizumab, state governments such as Maharashtra and Karnataka took a cue from the DCGI's approval to recommend itolizumab, given the drug's claimed benefit during the inflammatory phase of covid-19.

\section{Minimalistic medicine}

Keeping up with fast changing evidence is difficult for doctors on the frontline battling the pandemic. A few hospitals have taken a hard line against unproved drugs. The Mahatma Gandhi Institute of Medical Sciences explicitly prohibits the use of favipiravir, hydroxychloroquine, plasma, itolizumab, and tocilizumab in its treatment protocol.

Kalantri says that as a rural teaching hospital, the institute attracts poor patients, who would be unable to afford drugs like favipiravir, which costs around Rs450o ( $€ 45 ; \$ 62 ; € 51$ ) for a full course, or itolizumab, which costs Rs32 ooo for four doses. "What is the point in asking patients to pay through their noses for a drug, which has no clinically meaningful benefit?" he asks.

Another hospital, the Christian Medical College in Vellore, calls for these drugs to be used only in clinical trials. Priscilla Rupali, an infectious diseases specialist at the college, says her team wasn't convinced that current evidence supported the efficacy of these drugs. While doctors still have the choice to prescribe them, it would be unlikely for them to do so, given that the hospital's guidelines spell out the rationale behind the exclusion of these drugs, she says. In the case of favipiravir, an oral drug with high potential for abuse, the hospital has chosen to not even stock the drug in its pharmacy.

Such caution is relatively rare, however. Doctors do not always tell the patient's family about the unclear efficacy of these interventions. Santosh Gaggar's doctors were upfront about it. Her family agreed to the Rs5750 plasma treatment and she was transfused with an antibody rich extract of blood from recovered covid-19 patients with relatively little fuss, and she eventually recovered.

But when Deepak Vishwakarma, a resident of Bhopal, took his father to the city's Hamidia Hospital with severe covid-19 in mid-November the doctors said his father needed plasma but the hospital blood bank didn't have it. Vishwakarma says he struggled to procure the plasma from commercial blood banks, where there were shortages too. Eventually, a group of health rights activists helped him get hold of it.

He had been desperate. Yet Vishwakarma says that he had no idea the treatment he was searching for was unproved. "The doctors just told us that my father needed plasma. And he was so sick that we were willing to get him whatever he needed."

\section{Mounting evidence against plasma therapy}

In early January 2021, the investigators behind a Maharashtra state trial for plasma therapy in severely ill patients with covid-19 said they had stopped the trial prematurely after they found a higher rate of deaths and clotting in the intervention arm. It followed a randomised controlled study of over 450 moderately ill covid-19 patients, run by the ICMR, which suggested that the intervention wasn't useful to moderately ill patients. ${ }^{9}$ The ICMR recommended against the use of plasma in both moderately and severely ill patients who had been unwell for more than 10 days and whose bodies already had immunoglobulin $\mathrm{G}$, which is thought to appear 
in the body at roughly the same time as neutralising antibodies. This should have put a damper on plasma use in India, since the only patients in whom plasma seems to work ${ }^{10}$ are the mildly ill and roughly $98 \%$ of such patients recover on their own, says S P Kalantri, of Maharashtra's Mahatma Gandhi Institute of Medical Sciences.

Plasma therapy continues to be used routinely in parts of India, but there is mounting global evidence against what was considered one of the most promising treatments in the early days of the pandemic.

In November 2020, a randomised study published in the New England Journal of Medicine by Argentinian researchers found that plasma therapy didn't cut deaths in severely ill patients. ${ }^{11}$ In December 2020, a study suggested that the B.1.1.7 variant first identified in the United Kingdom had acquired mutations that help it evade human antibodies after an immunocompromised patient was treated thrice with plasma therapy for covid-19. ${ }^{12}$

In January 2021, the UK's RECOVERY trial closed recruitment to its plasma arm after researchers found that there was no difference in mortality between plasma recipients and controls in the more than 10000 people randomised to the trial. ${ }^{13}$

Competing interests: I have read and understood the BMJ policy on declaration of interests and declare: reporting for this article was funded by a grant from the Thakur Family Foundation, which did not influence the contents of the article.

Commissioning and peer review: Commissioned; not externally peer reviewed.

1 Indian Council of Medical Research. Evidence based advisory to address inappropriate use of convalescent plasma in covid-19 patients. 17 Nov 2020.

https://www.icmr.gov.in/pdf/covid/techdoc/ICMR_ADVISORY_Convalescent_plasma_17112020_v1.pdf.

2 The REMAP-CAP Investigators. Interleukin-6 receptor antagonists in critically ill patients with covid-19: preliminary report.MedRxiv2021.01.07.21249390 [Preprint]. https://www.medrxiv.org/content/10.1101/2021.01.07.21249390v2.

3 Pulla P. Is favipiravir good for covid-19? Clinical trial says no, press release says yes. The Wire 2020 Nov 25. https://science.thewire.in/the-sciences/favipiravir-glenmark-open-label-trial-primaryendpoints-efficacy-cure-times-misleading-press-release.

4 Kumar S, de Souza R, Nadkar M, etal. A two-arm, randomized, controlled, multi-centric, open-label phase-2 study to evaluate the efficacy and safety of itolizumab in moderate to severe ARDS patients due to covid-19.medRxiv2020.12.01.20239574 [Preprint]. https://www.medrxiv.org/content/10.1101/2020.12.01.20239574v1.

5 Hermine O, Mariette X, Tharaux P-L, Resche-Rigon M, Porcher R, Ravaud PCORIMUNO-19 Collaborative Group. Effect of tocilizumab vs usual care in adults hospitalized with covid-19 and moderate or severe pneumonia: a randomized clinical trial. JAMA Intern Med 2021;181:32-40. doi: 10.1001/jamainternmed.2020.6820. pmid: 33080017

6 Stone JH, Frigault MJ, Serling-Boyd NJ, etalBACC Bay Tocilizumab Trial Investigators. Efficacy of tocilizumab in patients hospitalized with covid-19. N Engl/ Med 2020;383:2333-44. doi: 10.1056/NEJMoa2028836. pmid: 33085857

7 Salvarani C, Dolci G, Massari M, etalRCT-TCZ-COVID-19 Study Group. Effect of tocilizumab vs standard care on clinical worsening in patients hospitalized with covid-19 pneumonia: a randomized clinical trial. JAMA Intern Med 2021;181:24-31. doi: 10.1001/jamainternmed.2020.6615. pmid: 33080005

8 Rosas I, Brau N, Waters M, etal. Tocilizumab in hospitalized patients with covid-19 pneumonia.medRxiv 2020.08.27.20183442 [Preprint]. doi: 10.1101/2020.08.27.20183442.

9 Agarwal A, Mukherjee A, Kumar G, Chatterjee P, Bhatnagar T, Malhotra PPLACID Trial Collaborators. Convalescent plasma in the management of moderate covid-19 in adults in India: open label phase II multicentre randomised controlled trial (PLACID Trial). BMJ2020;371:m3939. doi: 10.1136/bmj.m3939 pmid: 33093056

10 Libster R, Pérez Marc G, Wappner D, etalFundación INFANT-COVID-19 Group. Early high-titer plasma therapy to prevent severe covid-19 in older adults. N Engl / Med 2021. doi: 10.1056/NEJMoa2033700. pmid: 33406353

11 Simonovich VA, Burgos Pratx LD, Scibona P, etalPlasmAr Study Group. A randomized trial of convalescent plasma in covid-19 severe pneumonia. N Engl/ Med 2020. doi: 10.1056/NEJMoa2031304. pmid: 33232588

12 Carabelli AM, Robertson DL, Peacock S. Persistent SARS-CoV-2 infection and viral evolution tracked in an immunocompromised patient. COG-UK Consortium. 18 Dec 2020.

https://www.cogconsortium.uk/news_item/persistent-sars-cov-2-infection-and-viral-evolutiontracked-in-an-immunocompromised-patient.

13 Randomised evaluation of covid-19 therapy. RECOVERY trial closes recruitment to convalescent plasma treatment for patients hospitalised with covid-19. 15 Jan 2021. https://www.recoverytrial.net/news/statement-from-the-recovery-trial-chief-investigators-15-january-2021-recovery-trialcloses-recruitment-to-convalescent-plasma-treatment-for-patients-hospitalised-with-covid-19.
This article is made freely available for use in accordance with BMJ's website terms and conditions for the duration of the covid-19 pandemic or until otherwise determined by BMJ. You may use, download and print the article for any lawful, non-commercial purpose (including text and data mining) provided that all copyright notices and trade marks are retained. 